\title{
CRYSTAL STRUCTURE OF 3,4-DIHYDROXY-5-GERANYL-BENZOIC ACID
}

\author{
IVÁN BRITO*, ', MARIO J. SIMIRGIOTIS ${ }^{l}$, MARIA AVENDAÑO ${ }^{l}$, ALEJANDRA BRAVO', JORGE BORQUEZ ${ }^{l}$, \\ ALEJANDRO CÁRDENAS ${ }^{2}$
}

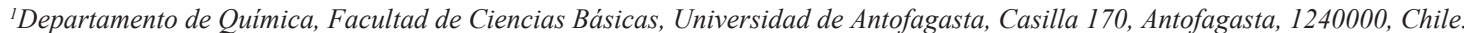

${ }^{2}$ Departamento de Física, Facultad de Ciencias Básicas, Universidad de Antofagasta, Casilla 170, Antofagasta, 1240000, Chile.

\begin{abstract}
The crystal structure of the aromatic compound 3,4-dihydroxy-5-geranyl-benzoic acid (5) is reported for the first time. This compound was isolated from the resinous exudate of Manto Negro (Heliotropium taltalense I. M. Johnst), an endemic species growing in The Atacama Desert using a combination of High speed counter current chromatography (HSCCC) and permeation through Sephadex LH-20. The structure was elucidated by spectroscopic means and confirmed by $\mathrm{X}$-ray crystal-structure analysis. All $\mathrm{OH}$ groups are involved in hydrogen bonding with the average $\mathrm{H} \cdots \mathrm{O}$ distance of $2.760(3) \AA$ and $\mathrm{O}-\mathrm{H} \cdots \mathrm{O}$ angles in the range $125-159^{\circ}$, so in the crystal packing the molecules are associated by three strong intermolecular hydrogen bonds forming ring with graph-set motif $\mathrm{R} 2^{2}(14) \mathrm{R} 2^{2}(6)$.
\end{abstract}

Keywords: New phenolic structure; benzoic acid derivative; flavonoids; Chilean plants; Heliotropium; NMR, X-ray diffraction.

\section{INTRODUCTION}

Heliotropium taltalense (Phil.) Johnst. (Heliotropiaceae) (Fig. 1) is an endemic species of the northern coast of Chile that produces a resinous exudate that covers its foliar surface and stems ${ }^{1}$. Several flavonoids and interesting geranyl aromatic derivatives were reported from this species and related ones. ${ }^{1}$ ${ }^{2}$ High speed counter current chromatography (HSCCC) is a support free liquidliquid partition chromatographic technique which eliminates the problem of the adsorption of a sample onto a solid support and has been widely used for the purification of natural products including a variety of flavonoids ${ }^{3}$. In the continuing efforts made by our laboratory in the search for new interesting metabolites from Paposo flora, ${ }^{4-5}$ several flavonoids and one new benzoic acid derivative (compounds 1-5, Fig. 2), were isolated from the resinous exudate by means of liquid-liquid high speed countercurrent chromatography (HSCCC). The structure of the new compound was elucidated by $1 \mathrm{D}$ and 2D NMR experiment and was confirmed by X-ray diffraction analysis of a single crystal obtained by slow evaporation of an ethyl acetate solution.

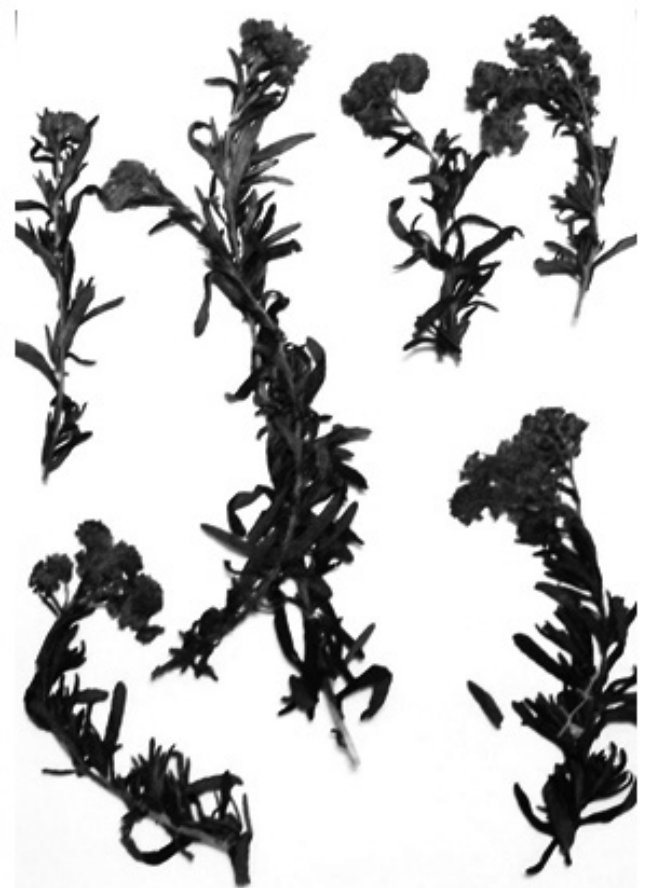

Fig. 1: Picture of an herborized sample of Manto Negro (Heliotropium taltalense (Phil.) Johnst. (Heliotropiaceae) collected in the Atacama Desert in november 2015.<smiles>[R6]c1ccc([C@@H]2CC(=O)c3c(O)cc([R6])cc3O2)cc1</smiles><smiles>COc1cc(O)c2c(=O)c(O)c(-c3ccc(O)cc3)oc2c1</smiles>

1. $\mathrm{R}_{1}=\mathrm{CH}_{3}, \mathrm{R}_{2}=\mathrm{H}$

2. $\mathrm{R}_{1}=\mathrm{H}, \mathrm{R}_{2}=\mathrm{H}$

3. $\mathrm{R} 1=\mathrm{OCH}_{3}, \mathrm{R} 2=\mathrm{OH}$<smiles>CC(C)=CCCC(C)=CCc1cc(C(=O)O)cc(O)c1O</smiles>

5.

Fig. 2. Structures of the compounds isolated from Manto Negro.

\section{EXPERIMENTAL}

Materials and Methods : TLC: Silica gel $60 \mathrm{~F}_{254}$ precoated plates (Merck). Column chromatography: Sephadex LH-20, MeOH as solvent. HSCCC: multilayer coil planet centrifuge contercurrent chromatograph Quattro MK7 equipped with two bobbins, each of them bearing two stainless steel coils (one bobbin bearing a $27 \mathrm{~mL}, 1 \mathrm{~mm}$ i.d. coil for analytical purposes + one 205 $\mathrm{mL} 2.1 \mathrm{~mm}$ i.d. preparative coil, and one bobbin bearing two $116 \mathrm{~mL}, 2.1$ $\mathrm{mm}$ i.d. preparative coils). The mobile phase was delivered with a constant pressure Series II SSI model HPLC pump and fractions were collected with a Gilson FC 203B model fraction collector. ${ }^{1} \mathrm{H}-$, and ${ }^{13} \mathrm{C}$ - and 2D NMR spectra: Bruker Avance 400 or Bruker Avance II 600 UltraShield spectrometers: $\delta$ in ppm rel. to $\mathrm{Me}_{4} \mathrm{Si}$ as internal standard, $J$ in $\mathrm{Hz}$. The melting point was measured in a Stuart Scientific melting point apparatus SMP3. HR-ESI-MS(-): Thermo Orbitrap Exactive Focus; in $m / z$. Single crystal structural X-ray diffraction was carried out on a Bruker AXS D8-Venture, Triumph- $\mathrm{I} \mu-\mathrm{Cu} \mathrm{CCD}$ area detector with graphite-monochromated $\mathrm{CuK} \alpha$ radiation $(1.54178 \AA$ ) diffractometer.

Heliotropium taltalense (Phil.) I. M. Johnst. aerial parts were collected in Quebrada de Paposo in June 2015. Voucher herbarium specimens are kept at the Natural Products Laboratory of the Universidad de Antofagasta under reference number: HT20150406.

Dried aerial parts of $H$. taltalense $(1.8 \mathrm{~kg})$ were immersed in ethyl acetate (EtOAc) for one minute (2 1) in order to obtain an extract from the exudate. The extract was immediately concentrated in vacuo and the resulting dark brown syrup $(47 \mathrm{~g})$. The isocratic two-phase non aqueous solvent system: $n$-hexane: ethyl acetate: methanol: water 3:7:5:5 $\mathrm{v} / \mathrm{v} / \mathrm{v}$ provided the better $\mathrm{K}$ values for all mayor compounds $(0.6<\mathrm{K}<1.5)$. This system was previously used for the 
separation of kaurenoic acids. ${ }^{3}$

Data collection, structural determination and refinement was performed with a Bruker AXS D8-Venture, Triumph- $\mathrm{I} \mu-\mathrm{Cu} \mathrm{CCD}$ area detector with graphite-monochromated $\mathrm{CuK} \alpha$ radiation $(1.54178 \AA$ ). The structure was solved by direct method, and was refined against $\mathrm{F}^{2}$ by full-matrix least-squares methods using SHELXL. ${ }^{11}$ All of the non-hydrogen atoms were refined anisotropically. The hydrogen atoms was located from a difference Fourier map and allowed to ride on their parent $\mathrm{C}$ atoms, with isotropic displacement parameters related to the refined values of the corresponding parent atoms. $\mathrm{H}$ atoms bonded to $\mathrm{O}$ atoms were freely refined with isotropic displacement parameters. The final Fourier maps, the electron-density residuals were not significant. Crystallographic data, details of data collection and structure refinement parameters for the title compound is summarized in Table 1. Program used to solve structure: SHELXS-2013, ${ }^{11}$ program used to refine structure: SHELXL-2013, ${ }^{11}$ molecular graphics. ${ }^{12}$

\section{RESULTS AND DISCUSSION}

After equilibration of the selected solvent system in a separatory funnel, the upper and lower working phases were separated and degassed in an ultrasonic bath for $15 \mathrm{~min}$ before use. The sample was prepared by dissolving $1000 \mathrm{mg}$ of exudate from $H$. taltalense in $4.0 \mathrm{~mL}$ of each phase of the solvent system, filtered and loaded into an injection valve (Rheodyne model 5010A) equipped with a $8 \mathrm{~mL}$ loop. The preparative coil $(116 \mathrm{ml})$ was filled with the upper stationary phase and the apparatus was rotated at $850 \mathrm{rpm}$. The mobile lower phase was then pumped in a Head to Tail direction (H-T) at a flow rate of $5 \mathrm{~mL}$-minute. After the mobile phase front emerged and the hydrodynamic equilibrium was established in the column, the percentage of the retention of the stationary phase $(65 \%)$ was recorded. Then the sample was injected thorough the injection valve at a flow rate of $5 \mathrm{~mL}$-minute. The fractions eluted were collected with the fraction collector $\left(5 \mathrm{ml}\right.$ each) and analyzed by TLC $\left(\mathrm{F}_{254}\right.$ Silica gel Plates, developed with hexane:EtOAc, 1:1 v/v, and spots visualized by spraying with vanillin:sulfuric acid $2 \%$ in ethanol and heating. CCC rotation was interrupted in tube 60 and the coil content was collected ("washoff'), originating 85 fractions of $6 \mathrm{~mL}$ each. After re-purification by sephadex LH 20 (solvent methanol), HSCCC fractions 30-32 afforded compound 1, (pinostrobin, ${ }^{6-9} 5$-hydroxy-7-methoxyflavanone, $10 \mathrm{mg}$, Fig. 2), fractions 3334 compound 2 (pinocembrin, ${ }^{6-9} 5,7$ - dihydroxyflavanone, $12 \mathrm{mg}$ ), fractions 35-37 compound 3 (sakuranetin, ${ }^{8-10} 5$, 4' -dihydroxy-7-methoxyflavanone), $11.5 \mathrm{mg}$ ), fractions 35-37 compound 4 (7-methoxy-kaempferol) and fractions 75-78 the new compound 5 (3, 4 dihydroxy-5-geranyl-benzoic acid, $30 \mathrm{mg}$ ). The physical and spectral data of compound $\mathbf{5}$ are as follow: White crystals, m.p. $131-132{ }^{\circ} \mathrm{C}$. [M-H] : $289.1437,[\mathrm{M}+\mathrm{H}]^{+}: 291.1440$. Uv: 266-300sh. ${ }^{1} \mathrm{H}$ NMR (Bruker Avance $300 \mathrm{MHz}, \mathrm{MeOD}) \delta$ ppm: Please see Table $2 .{ }^{13} \mathrm{C}$ NMR (300 MHz, MeOD) $\delta$ ppm: see Table 2. These data, together with ESI-MS and correlations observed in the HSQC and HMBC spectra, are consistent with the proposed structure.

Table 1. Crystallographic data, details of data collection and structure refinement parameters for the title compound.

\section{Crystal data \\ $\mathrm{C}_{17} \mathrm{H}_{22} \mathrm{O}_{4}$ \\ $\mathrm{Mr}=290.34$}

Monoclinic, $\mathrm{P} 21 / \mathrm{c}\left(\mathrm{N}^{\circ} 14\right)$

$\mathrm{a}=16.5643(5) \AA \quad \alpha=90^{\circ}$

$\mathrm{b}=8.7246(3) \AA \quad \beta=90.783(2)^{\circ}$

$\mathrm{c}=11.1681(3) \AA \quad \gamma=90^{\circ}$

$\mathrm{mm}$

Density (calculated) $/ \mathrm{Mg} / \mathrm{m}^{3} 1.195$

Data Collection

Bruker AXS D8-Venture, Triumph-I $\mathrm{I}-\mathrm{Cu}$

$\mathrm{CCD}$ area detector diffractometer

14540 measured reflections

2329 independent reflections

Theta range for data collection $(\theta)$

Index ranges

Refinement

$\mathrm{R}\left[\mathrm{F}^{2}>2 \sigma\left(\mathrm{F}^{2}\right)\right]=0.0581$

$\mathrm{wR}\left[\mathrm{F}^{2}\right]==0.1624$

$\mathrm{S}=1.051$

Extinction coefficient $0.0026(5)$
Four flavonoids and a new benzoic acid derivative (Fig. 2) were rapidly isolated by means of HSCCC and the structures of the known and new compound elucidated by NMR. The molecular formula $\mathrm{C}_{17} \mathrm{H}_{22} \mathrm{O}_{4}$ assigned to the new compound 5 was determined by analysis of the ${ }^{13} \mathrm{C}$ NMR data associated with HR-HESI (-) MS (Fig. 3, required: 289.1445, found: 289.1437, $\mathrm{C}_{17} \mathrm{H}_{21} \mathrm{O}_{4}^{-}$, $\left.[\mathrm{M}-\mathrm{H}]^{-}\right)$. The IR spectrum indicated the presence of an hydroxyl group (3.301 $\left.\mathrm{cm}^{-1}\right)$, a carboxyl acid (2970-2547 and $\left.1673 \mathrm{~cm}^{-1}\right)$ and signals attributed to an aromatic ring (1598 and $781 \mathrm{~cm}^{-1}$ ). The ${ }^{1} \mathrm{H}$ NMR spectra of the new compound 5 (Table 2) showed three methyl groups signal assigned to several methylenes, methines and aromatic protons, including signals for two aromatic protons at $\delta$ $7.40(\mathrm{~d}, \mathrm{~J}=1.9)$ and $\delta 7.35(\mathrm{~d}, \mathrm{~J}=1.9)$, suggesting a 1,2-disubstituted aromatic ring in the molecule. The spectrum also displayed signals for three vinyl methyl groups at $\delta 1.64,1.72$ and 1.58; three allylic methylene groups (one appeared as a doublet at $\delta 3.34(2 \mathrm{H}, \mathrm{J}=6.7 \mathrm{~Hz})$. Additionally, signals for two olefinic protons at $\delta 5.10(1 \mathrm{H}$, ddd, $\mathrm{J}=6.8,3.9,1.2)$ and $5.34(1 \mathrm{H}, \mathrm{td}, \mathrm{J}=6.7$ $\mathrm{Hz}$ ), were observed. The ${ }^{13} \mathrm{C}$ NMR spectrum of compound 5 exhibited 17 peaks (Table 2) while the DEPT-135 showed evidence 3 methyls, 3 methylenes, 4 methines and 7 quaternary (including one carbonyl) carbons. The ${ }^{13} \mathrm{C}$ NMR (Table 2) spectrum exhibited signals in the low-field region corresponding to one carboxyl acids (at $\delta 169.3$ ) and six aromatic carbons (at $\delta 113.7,120.1$, $122.8,127.7,144.0$ and 148.1) along with signals for four olefinic and six sp ${ }^{3}-$ hybridized carbons. All these data suggested that $\mathbf{5}$ is a benzoic acid derivative with a geranyl chain. Similar compounds were isolated from resinous exudates of other Heliotropium. ${ }^{1,2,8}$ The assignment of the ${ }^{1} \mathrm{H}$ and ${ }^{13} \mathrm{C}$ NMR data were supported on 2D experiments and comparison with data already reported for other benzoic acid analogues. ${ }^{13-15}$ In particular the HMBC and HSQC experiments were key in the elucidation of the structure (Table 2).

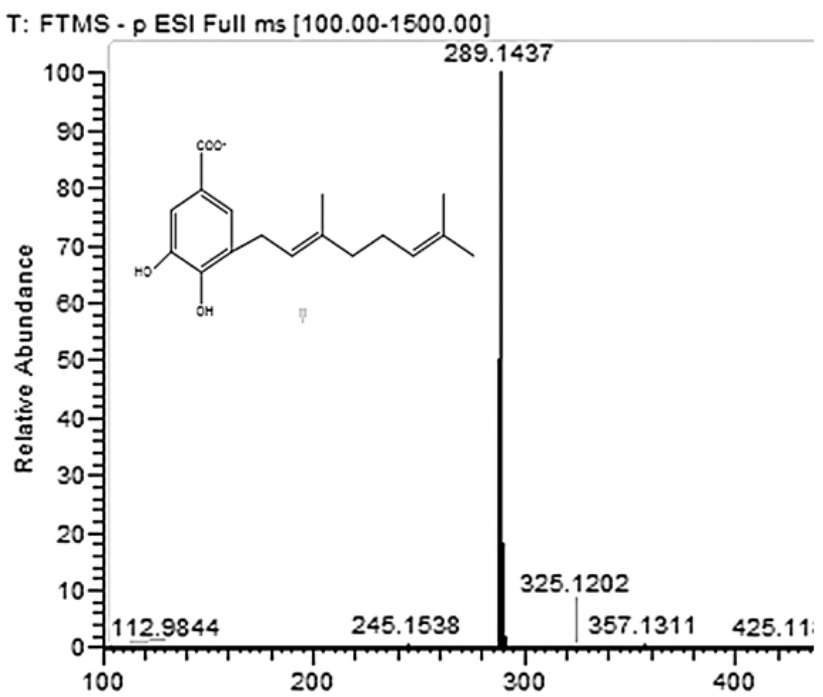

Fig. 3: Full Orbitrap HESI (-) spectra of compound 5.

The structure of compound $\mathbf{5}$ was confirmed by $\mathrm{x}$-ray diffraction analysis of a suitable single crystal (Fig. 4). Yellow block crystals of 3,4-dihydroxy5 -geranyl-benzoic acid of approximate dimensions $0.35 \times 0.25 \times 0.20 \mathrm{~mm}$ were obtained by slow evaporation of a ethyl acetate solution. The dihydroxy benzoic acid fragment is planar (rms deviations $0.016 \AA$ ). All OH groups are involved in hydrogen bonding with the average $\mathrm{H} \cdots \mathrm{O}$ distance of $2.760(3)$ $\AA$ and $\mathrm{O}-\mathrm{H} \cdots \mathrm{O}$ angles in the range $125-159^{\circ}$, so in the crystal packing the molecules are associated by three strong intermolecular hydrogen bonds forming ring with graph-set motif $\mathrm{R} 2^{2}(14) \mathrm{R} 2^{2}(6)$, Table 3 . These two types of rings combine alternately in an $\cdots \mathrm{ABAB} \cdots$ fashion to form a one dimensional supramolecular aggregate (Fig.5) along $\mathrm{b}$ axis. The packing also features and $\pi-\pi$ stacking interactions between the 3,4-dihydroxy benzoic acid fragment [Cg-Cgi distance 3.691(3) $\AA$; symmetry code (i) $-\mathrm{x}, 1-\mathrm{y},-\mathrm{z} ; \mathrm{Cg}=\mathrm{C} 1 / \mathrm{C} 2 / \mathrm{C} 3 /$ $\mathrm{C} 4 / \mathrm{C} 5 / \mathrm{C} 6]$. All bond distances and angles are normal. 
Table 2. ${ }^{1} \mathrm{H}(400 \mathrm{MHz})$ and ${ }^{13} \mathrm{C}$ NMR $(100.25 \mathrm{MHz})$ data, HMBC and COSY correlations for compound $\mathbf{5}$ in MeOD (J in Hz in parentheses).

\begin{tabular}{|c|c|c|c|c|}
\hline Position & $\delta(\mathbf{C})$ & $\begin{array}{c}\delta(\mathbf{H}) \text { mult. } \\
(\mathrm{J} \text { in Hz) }\end{array}$ & $\begin{array}{c}\text { COSY } \\
(\mathrm{H} \rightarrow \mathrm{H})\end{array}$ & $\begin{array}{l}\mathrm{HMBC} \\
(\mathrm{H} \rightarrow \mathrm{C})\end{array}$ \\
\hline 1 & $120.1(s)$ & & & \\
\hline 2 & $122.8(d)$ & $7.40(d, J=1.9)$ & H-6 & $\mathrm{C}-3, \mathrm{COOH}$ \\
\hline 3 & $127.7(s)$ & & & \\
\hline 4 & $148.1(s)$ & & & \\
\hline 5 & $144.0(s)$ & & & \\
\hline 6 & $113.7(d)$ & $7.35(d, J=1.9)$ & $\mathrm{H}-2$ & $\mathrm{C}-1, \mathrm{COOH}$ \\
\hline 1 ' & $27.5(\mathrm{t})$ & $3.34(d, J=6.7)$ & $\mathrm{H}-2^{\prime}$ & $\mathrm{C}-4,5,2^{\prime}, 3^{\prime}$ \\
\hline $2^{\prime}$ & $124.0(d)$ & $5.34(t d, J=7.3,1.1)$ & $\mathrm{H}-1$ & C-9', 4' \\
\hline $3^{\prime}$ & $135.8(s)$ & & & \\
\hline $4^{\prime}$ & $39.5(t)$ & $\begin{array}{c}2.07(t d, J=12.3, \\
6.3)\end{array}$ & $\mathrm{H}-5$ & $\mathrm{C}-2^{\prime}, 3^{\prime}, 5^{\prime}$ \\
\hline 5 , & $25.3(t)$ & $\begin{array}{c}2.07(t d, J=12.3, \\
6.3)\end{array}$ & $\mathrm{H}-4$ & $\mathrm{C}-4^{\prime}, 6^{\prime}, 7^{\prime}$ \\
\hline 6 ' & $122.1(d)$ & $\begin{array}{c}5.10(d d d, \\
J=6.8,3.9,1.2)\end{array}$ & $\mathrm{H}-5$ & $C-5^{\prime}, 7^{\prime}$ \\
\hline $7^{\prime}$ & $130.8(\mathrm{~s})$ & & & \\
\hline $8^{\prime}$ & $24.5(\mathrm{q})$ & $1.64(s)$ & H-10', 6' & $\mathrm{C}-6^{\prime}, 7^{\prime}$ \\
\hline 9' & $14.9(\mathrm{q})$ & $1.72(s)$ & $\mathrm{H}-2^{\prime}$ & C-4', 3' \\
\hline $10^{\prime}$ & $16.4(\mathrm{q})$ & $1.58(s)$ & H-8 & $\mathrm{C}-6^{\prime}, 7^{\prime}, 8^{\prime}$ \\
\hline $\mathrm{COOH}$ & $169.3(\mathrm{~s})$ & & & \\
\hline
\end{tabular}

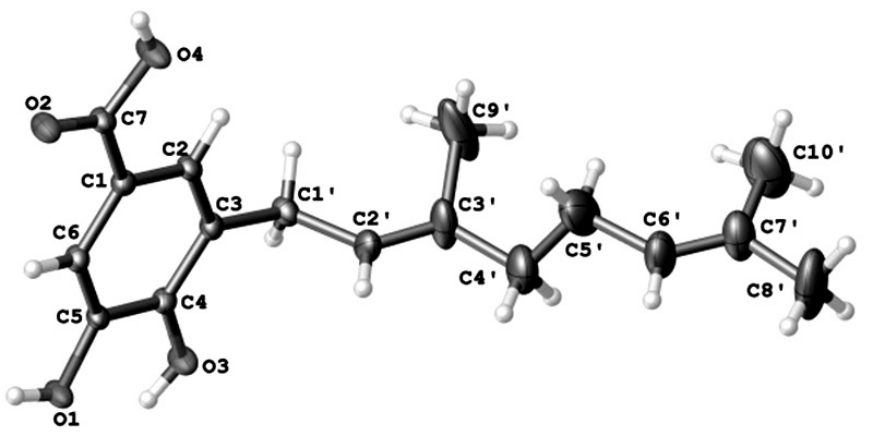

Fig. 4. ORTEP drawing of the molecular structure of 5

Table 3: Hydrogen-bonding geometry $\left(\AA,^{\circ}\right)$.

Symemetry codes: (i) $\mathrm{x}, 1+\mathrm{y}, \mathrm{z}$; (ii) $-\mathrm{x}, 1 / 2+\mathrm{y}, 1 / 2-\mathrm{z}$; (iii) $-\mathrm{x},-1 / 2+\mathrm{y}, 1 / 2-\mathrm{z}$.

\begin{tabular}{|c|c|c|c|c|}
\hline $\mathrm{D}-\mathrm{H} \cdots \mathrm{A}$ & $\mathrm{D}-\mathrm{H}$ & $\mathrm{H} \cdots \mathrm{A}$ & $\mathrm{D} \cdots \mathrm{A}$ & $\mathrm{D}-\mathrm{H} \cdots \mathrm{A}$ \\
\hline $\mathrm{O} 1-\mathrm{H} 1 \cdots \mathrm{O} 2^{\mathrm{iii}}$ & $0.83(3)$ & $1.90(3)$ & $2.715(3)$ & $169(3)$ \\
\hline $\mathrm{O} 3-\mathrm{H} 3 \cdots \mathrm{O} 2^{\mathrm{ii}}$ & $0.83(3)$ & $2.28(3)$ & $2.824(3)$ & $124(3)$ \\
\hline $\mathrm{O} 4-\mathrm{H} 4 \cdots \mathrm{O} 3^{\mathrm{i}}$ & $0.90(3)$ & $1.88(3)$ & $2.738(3)$ & $158(3)$ \\
\hline
\end{tabular}

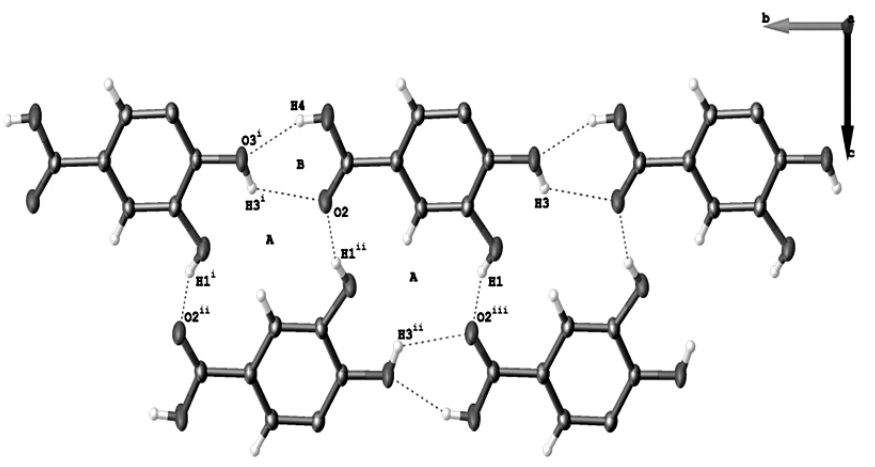

Fig. 5. A view of the one-dimensional supramolecular aggregate, showing the formation of set-graph motif $\mathrm{R} 2^{2}(14) \mathrm{R} 2^{2}(6)$, rings (labelled A and $\mathrm{B}$, respectively [Symmetry codes: (i) $\mathrm{x}, 1+\mathrm{y}, \mathrm{z}$; (ii) $-\mathrm{x}, 1 / 2+\mathrm{y}, 1 / 2-\mathrm{z}$; (iii) $-\mathrm{x}$, $-1 / 2+y, 1 / 2-z]$. The lateral chain of the title compound has been omitted for clarity.

\section{CONCLUSIONS}

In summary we have isolated the compound 3,4-dihydroxy-5-geranylbenzoic acid from the resinous exudate of Manto Negro (Heliotropium taltalense I. M. Johnst), an endemic species growing in the Atacama desert using a combination of High speed counter current chromatography (HSCCC) and permeation through Sephadex LH-20 and its structure was elucidated by spectroscopic means and confirmed by X-ray crystal-structure analysis. In the crystal packing the molecules are associated by three strong intermolecular hydrogen bonds forming ring with graph-set motif $\mathrm{R}^{2}(14) \mathrm{R} 2^{2}(6)$. These two types of rings combine alternately in an $\cdots \mathrm{ABAB} \cdots$ fashion to form a bidimensional supramolecular aggregate along $\mathrm{b}$ axis.

\section{ACKNOWLEDGEMENTS}

The authors thank FONDECYT (Chile) (Grant 1140178) for financial 
support. We also acknowledge Fondequip (EQM130021 and EQM140002) for the funding to purchase the $\mathrm{X}$ - ray diffractometer and the HR-Orbitrap MS equipment. We also thank to the Corporación Nacional Forestal of Chile (CONAF) for allowing us to collect plants and fruits in the national protected areas of Northern Chile belonging to SNASPE (National System of Protected Areas of Chile).

Supplementary material

CCDC- 1432150 contains the supplementary crystallographic data for this article. These data can be obtained free of charge from the Cambridge Crystallographic Data Centre via www.ccdc.cam.ac.uk/data_request/cif.

\section{REFERENCES}

1. B. Modak, M. Rojas, R Torres, Molecules 1980, 14, (2009).

2. R. Torres, L Villaroel, A Urzua, F Delle Monache, G Delle Monache, E. Gacs-Baitz. Phytochemistry, 249, 36, (1994).

3. K. Skalicka-Wozniak, I. Garrard, Phytochem Ver. 547, 13, (2014)

4. M. J. Simirgiotis, J. Bórquez, M. Neves-Vieira, I. Brito, S. Alfaro-Lira, P. Winterhalter, C. Echiburú-Chau, G. Jerz, A. Cárdenas, Ind. Crops Prod. 76, 69, (2015)
5. J. Bórquez, E. J. Kennelly, M. J. Simirgiotis, Food Res. Int. 52, 288, (2014).

6. P. K. Agrawal, Carbon-13 NMR of flavonoids. Michigan, Elsevier. 1989

7. M. Gajhede, E. R. Leal, G. C. Patino, J. C. Christophersen, P. H. Nielsen, Acta Cryst. 2012, C45, (1989).

8. R. Torres, B. Modak, L. Villarroel, A. Urzua, F. Delle-Monache, Bol. Soc. Chil. Quím. 195, 41, (1996).

9. H. D. Smolarz, E. Mendyk, A. Bogucka-Kocka, Zeitsch. Naturforsch., 64, 61c, (2006)

10. R. D. Torrenegra, O. E. Rodriguez, Nat. Prod. Commun. 947, 6, (2011).

11. G. M. Sheldrick, Acta Cryst. 112 , A64, (2008)

12. O.V. Dolomanov, L.J. Bourhis, R.J. Gildea, J.A.K. Howard, H. Puschmann, J. Appl. Cryst.339, 42, (2009).

13. N. Flores, I. A. Jiménez, A. Giménez, G. Ruiz, D. Gutiérrez, G. Bourdy, I. L. Bazzocchi, Phytochemistry 621, 70, (2009).

14. T. P. Green, E. M. Treadwell, D. F. Wiemer. J. Nat. Prod. 367, 62, (1999).

15. N. Flores, I. A. Jiménez, A. Giménez, G. Ruiz, D. Gutiérrez, G. Bourdy, I. L. Bazzocchi, J. Nat. Prod. 1538, 71, (2008). 